\title{
RBP increases its impact factor again and is progressively more cited in other journals
}

\section{A RBP novamente aumenta o fator de impacto sendo cada vez mais citada em outras revistas}

We were glad to learn that RBP's impact factor (IF), announced by the Institute for Scientific Information (ISI), Thomson Reuters - Journal Citation Reports, increased for the third consecutive time, now from 1.391 to 1.593 (graph 1), which represents an increment of $15 \%$. These figures gain even more meaning if we consider the concomitant decrease in RBP's citations of its own articles, from $28 \%$ in 2009 to $18 \%$ in 2010 .

Our IF has climbed from the fifth to the second position among all 102 ISI-indexed scientific journals published in Brazil, regardless of area, and now ranks fourth in Latin America. We have the highest IF in Latin America and the second highest in the Southern Hemisphere in the field of psychiatry and neuroscience. Although aware of the limitations and ambiguities surrounding IF, we believe that these results arise from the continuous increase in higher-quality submissions; added to the work and dedication of our editorial board and external referees. The constant support of the Brazilian Psychiatric Association and its commitment to expanding the access to and visibility of the RBP also deserve to be highlighted.

Graph 1: Evolution of RBP's impact factor compared to the rate of self-citations

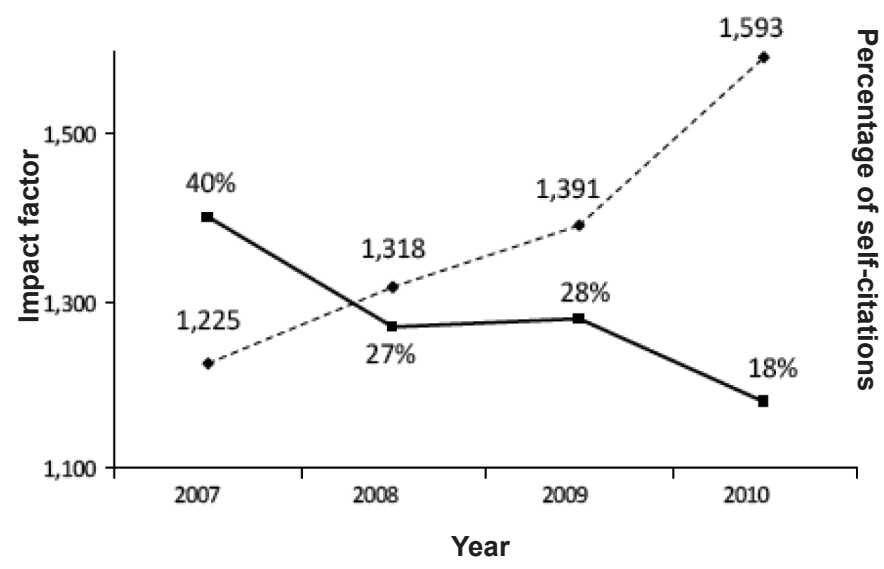

Always seeking to publish articles of high scientific relevance on global mental health topics with the potential to be translated into clinical practice, we are aware of the need to move on with constant growth and evolution ${ }^{1,2}$. As from 2012, targeting extended international penetration, all articles in the RBP will be published in English. Nonetheless, a review or update article will be made available in two languages (Portuguese and English) in each issue. Furthermore, published articles will include text boxes designed to translate the main research findings into the clinical context.

Thus, the RBP strives to maintain its space conquered over the last decade by following the path of evolution of the Brazilian scientific production in the areas of psychiatry, neuroscience and mental health ${ }^{3}$ and by expanding its international excellence.

José Alexandre S. Crippa, Rodrigo A. Bressan, Giovanni Abrahão Salum, João Quevedo, Christian Kieling, Marcelo Queiroz Hoexter, Tais Moriyama, Marcos Hortes N. Chagas, Leonardo Fontenelle, Guilherme Vanoni Polanczyk, Marcelo Pio de Almeida Fleck

References

1. Salum GA, de Souza Crippa JA, Affonseca-Bressan R, Kieling C, Tavares H, Hoexter MQ, Moriyama T, Fontenelle L, Polanczyk GV, de Almeida Fleck MP. Opinion poll: listening to the RBP's readers. Rev Bras Psiquiatr. 2010;32(4):331-2. 2. Lafer B, Diniz JB, Polanczyk GV, Fontenelle LF, Tavares H, Fleck MP, Bressan RA. The RBP's mission in the continuing medical education. Rev Bras Psiquiatr. 200931(1):2-3.

3. Leite JP. The new QUALIS and the evaluation of Brazilian Graduate Programs in the medical area: myths and reality. Rev Bras Psiquiatr. 2010;32(2):103-5. 